\title{
Long-Term Traumatic and Asymptomatic Aorto-Right Atrial Fistula
}

Sandro Gonçalves de Lima ${ }^{1,2}$, MD, PhD; Andréa Bezerra de Melo da Silveira Lordsleem ${ }^{1,2}, \mathrm{MD}, \mathrm{PhD}$; Kaique Leal Campos $^{1}$, MD; Juliana Guedes Silva ${ }^{1}$, MD; Marcelo Antônio Oliveira Santos ${ }^{2}$, MD; Brivaldo Markman Filho ${ }^{1}$, MD, PhD

\section{电}

DOI: $10.21470 / 1678-9741-2018-0296$

\begin{abstract}
Aorto-atrial fistulas due to cardiac trauma are rare, and survivors require immediate surgical correction. Here, we report a case of an aorto-right atrial fistula due to penetrating trauma after a 16-year evolution, which developed symptoms of acute coronary
\end{abstract}

\begin{tabular}{ll}
\hline \multicolumn{2}{l}{ Abbreviations, acronyms \& symbols } \\
\hline ARAF & $=$ Aorta-right atrial fistula \\
RA & $=$ Right atrium \\
TEE & $=$ Transesophageal echocardiography \\
\hline
\end{tabular}

\section{INTRODUCTION}

The aorta-right atrial fistula (ARAF) is a rare aortic-chamber connection that may originate from one of the three sinuses of Valsalva. Traumatic cause is rare and commonly associated with the need for emergency surgical correction ${ }^{[1]}$.

Victims of cardiac trauma who have survived intracardiac lesions such as ventricular septal defect, ARAF and aorta-ventricle fistula, with sufficient time to undergo corrective surgery are rare ${ }^{[2]}$.

We report a case of ARAF after a penetrating thoracic trauma due to a cold weapon after 16 years of evolution.

\section{Clinical Data}

A 66-year-old male, hypertensive, smoker, reported epigastric pain, irradiated to the mandible, associated with sweating two years before admission. Four months before admission he had syndrome and was treated with myocardial revascularization and correction of the aorto-cameral fistula.

Keywords: Fistula/Surgery. Heart Atria. Wounds, Penetrating. Wounds and Injuries. Heart Injuries.
'Department of Cardiology, Hospital das Clínicas at Universidade Federal de Pernambuco (HC-UFPE), Recife, PE, Brazil.

2Epidemiology and Cardiology Research Group, Recife, PE, Brazil.

The study was carried out at the Department of Cardiology, Hospital das Clínicas at Universidade Federal de Pernambuco (HC-UFPE), Recife, PE, Brazil. presented paroxysmal nocturnal dyspnea, orthopnea, lower limb edema, asthenia, visual turbidity and dizziness. A previous history of precordial trauma due to a cold weapon, 16 years before, was treated only with pleural drainage.

In the physical examination, a scar was observed on the right parasternal line at the level of the fifth intercostal space, due to the cold weapon injury, jugular turgor at $90^{\circ}$, mesocardial impulsion with no thrill. Regular two-stroke heart rhythm with continuous $3+/ 6+$ murmur in the accessory aortic and aortic focus, and hyperphoneme components A2 and P2.

\section{Electrocardiography}

First-degree atrioventricular block. Signs of left ventricular overload and slow $\mathrm{R}$ wave growth in the anterolateral wall (Figure 1).

\section{Radiography}

Increased cardiac chambers, especially right and left atria, and increased pulmonary vascular markings (Figure 2).

\section{Transthoracic Echocardiography}

Left ventricular ejection fraction of $41.1 \%$, septal hypokinesia, right chamber dilatation, right ventricle with diffuse 


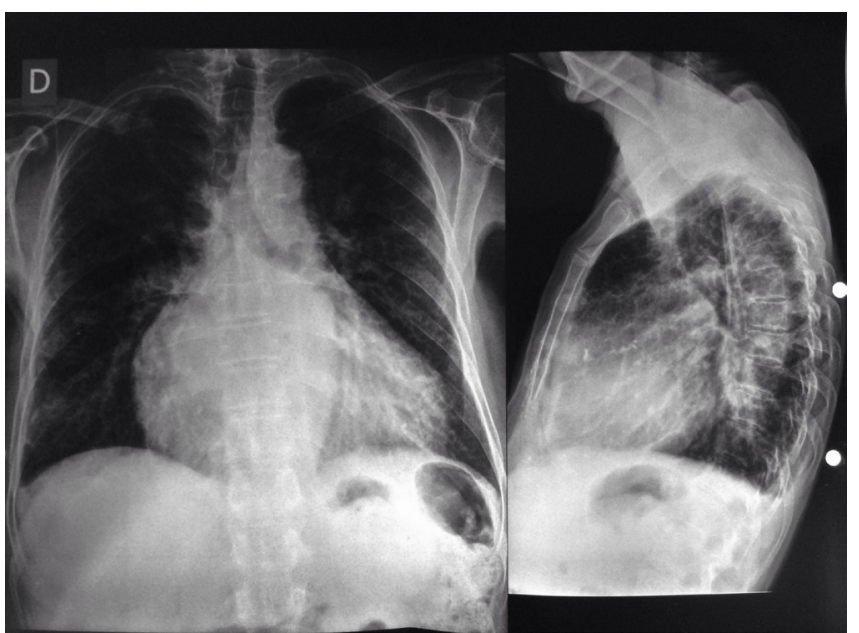

Fig. 1 - Posterior-anterior (left) and profile (right) chest radiography.

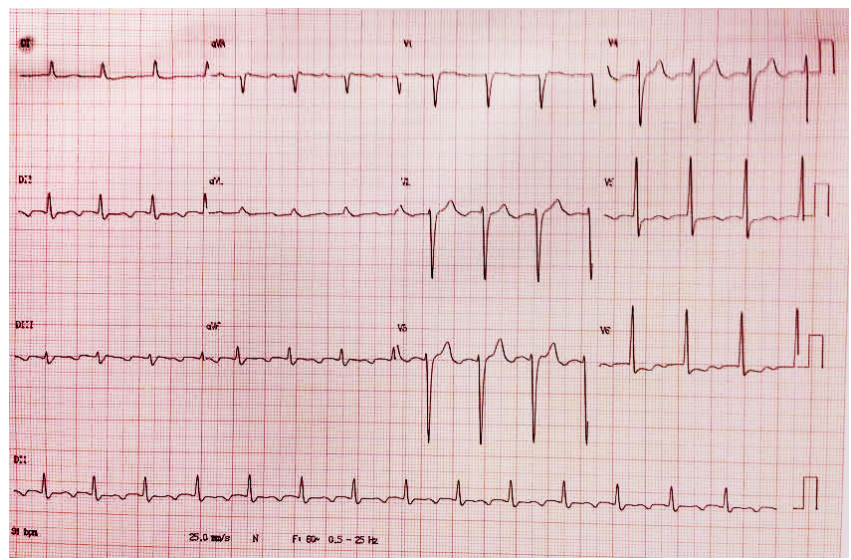

Fig. 2 - Electrocardiogram.

hypocontratility (tricuspid annular plane systolic excursion $=15$ $\mathrm{mm}$ ), and systolic and diastolic flow of the right coronary aortic sinus into the right atrium (RA).

\section{Diagnosis and Surgery}

Cineangiocoronariography demonstrated a severe distal lesion in the trunk of the left coronary artery, anterior descending with severe proximal lesion, circumflex occluded in the distal third and right coronary with no significant lesions (Movie 1). In aortography, the ascending aorta exhibited a preserved caliber, a right ventral sinus rupture image with consequent formation of ARAF (Figure 3, Movies 2 and 3).

The patient underwent surgical correction of the fistula by direct suture and myocardial revascularization (left internal thoracic artery-anterior descending, saphenous vein graft from the aorta to two marginal branches), with good evolution.

\section{DISCUSSION}

We have encountered only one report of ARAF through trauma from a cold weapon, described by Swanepoel et al. ${ }^{[3]}$.
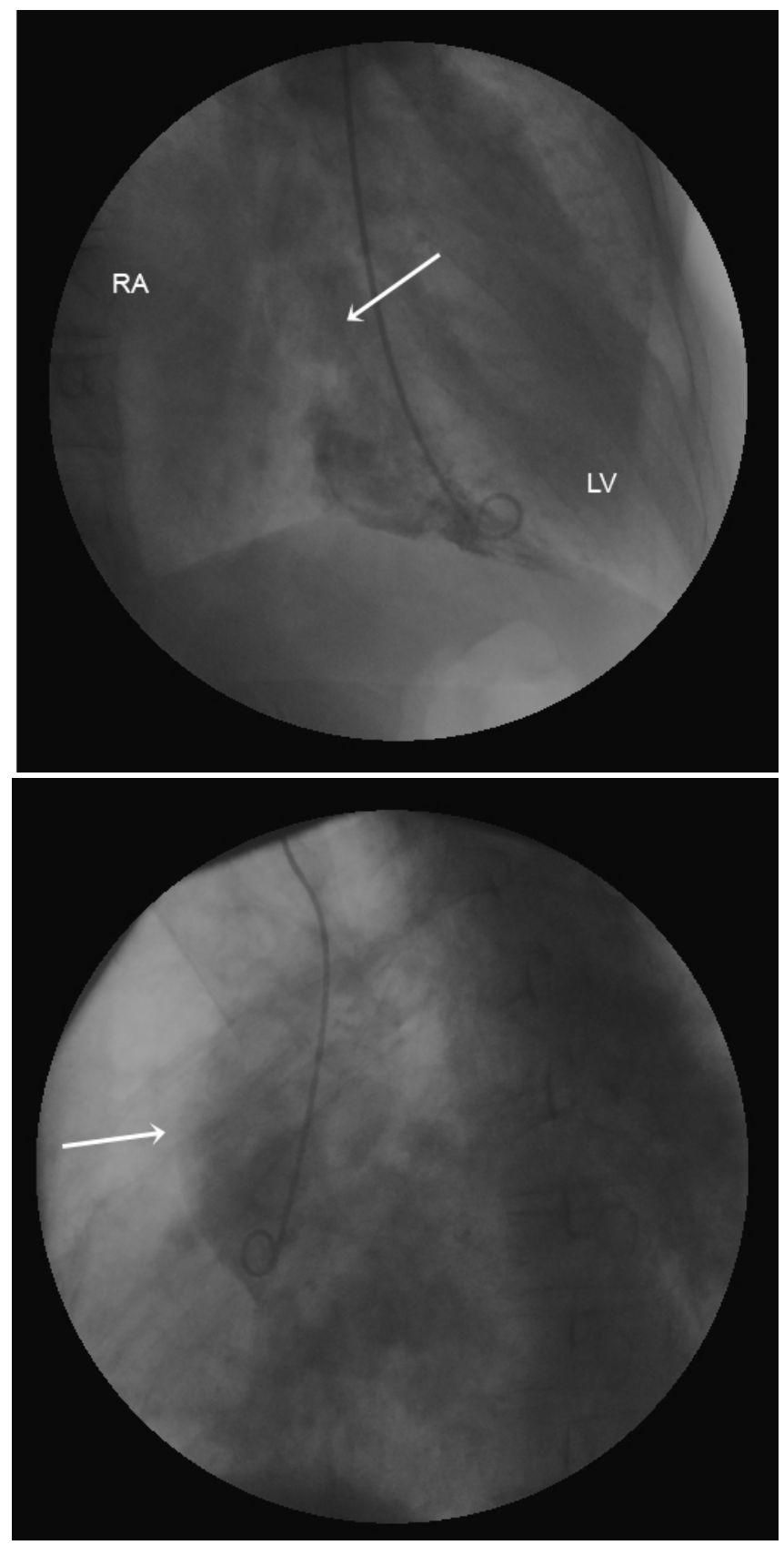

Fig. 3 - Ascending aorta aortography: blood flow (white arrow) from the aorta to the right atrium (RA). $L V=$ left ventricle

However, in this case, the patient presented with symptoms of rapidly progressive heart failure in the first four days after the trauma. Stable evolution over a period as long as 16 years, as presented by our patient, demonstrates the rarity of the case herein described.

In patients with asymptomatic aorto-chamber fistula, clinical findings depend on the affected chamber. The presence of a continuous murmur appears to be present in most cases of ARAF described, as well as in ours ${ }^{[3-6]}$. In general terms, diagnosis is possible through transesophageal echocardiography (TEE), 
Video 1 - Cineangiocoronariography.

Video 2 - Aortography of the ascending aorta.

Video 3 - Aortography of the ascending aorta.

which demonstrated a communication between the flow from the aorta to the cardiac chamber. However, cardiac angiography is the gold standard for the diagnosis of fistula and is indicated when TEE is inconclusive.

Early surgical repair is recommended as the treatment of choice, given the need to prevent the development of symptoms and serious complications such as ventricular overload, bacterial endocarditis, pulmonary vascular disease, aneurysm formation and the risk of spontaneous rupture ${ }^{[7,8]}$. The closure of the ARAF by transcatheter device has been considered an innovative method and may be used as an alternative to the traditional surgical approach in selected cases $^{[8]}$.

\section{Authors' roles \& responsibilities}

SGL Conception and study design; manuscript redaction or critical review of its content; final manuscript approval

ABMSL Conception and study design; manuscript redaction or critical review of its content; final manuscript approval

KLC Manuscript redaction or critical review of its content; final manuscript approval

JGS Manuscript redaction or critical review of its content; final manuscript approval

MAOS Manuscript redaction or critical review of its content; final manuscript approval

BMF Manuscript redaction or critical review of its content; final manuscript approval

\section{REFERENCES}

1. Erkal Z, Bayar N, Çağırcı G, Arslan Ş. Incidentally detected aorto-right atrial fistula in asymptomatic patient with operated aortic dissection. Int J Cardiovasc Acad. 2017:3(1-2):57-8.

2. Mulder DG. Stab wound of the heart. Ann Surg. 1964;160(2):287-91.

3. Swanepoel A, Schrire V, Nellen M, Vogelpoel L, Barnard C. Traumatic aortic-right atrial fistula: report of a case corrected by operation. Am Heart J. 1961;61(1):120-5.

4. Kalra A, Kohl LP, Asinger RW, Bachour FA, Van Camp JR, Ayenew W, et al. Aorto-right atrial fistula at aortotomy site following surgical myectomy. Echocardiography. 2013;30(9):E300-1.

5. Chang H, Chu SH, Lee YT. Traumatic aorto-right atrial fistula after blunt chest injury. Ann Thorac Surg. 1989;47(5):778-9.

6. Morgan S, Maturana G, Urzua J, Franck R, Dubernet J. Elective correction of intracardiac lesions resulting from penetrating wounds of the heart. Thorax. 1979;34(4):459-63.

7. Cavelluci PMSM, Pimentel BDPA, Trandafilov MD, Linhares RR, Silva CES, Monaco CG, et al. Fístula aorta-átrio direito, simulando CIV, com fechamento percutâneo por prótese CERA ${ }^{\oplus}$. Rev Bras Ecocardiogr Imagem Cardiovasc. 2013;26(2):125-8.

8. Said SAM, Mariani MA. Acquired aortocameral fistula occurring late after infective endocarditis: an emblematic case and review of 38 reported cases. World J Cardiol. 2016;8(8):488-95. 